\title{
Increased sympathetic and decreased parasympathetic cardiovascular modulation in normal humans with acute sleep deprivation
}

\author{
Xu Zhong, ${ }^{1}$ H. John Hilton, ${ }^{2}$ Gregory J. Gates, ${ }^{3}$ Sanja Jelic, ${ }^{1}$ Yaakov Stern, ${ }^{2}$ \\ Matthew N. Bartels, ${ }^{3}$ Ronald E. DeMeersman, ${ }^{3,4}$ and Robert C. Basner ${ }^{1}$ \\ Departments of ${ }^{1}$ Medicine, ${ }^{2}$ Neurology, and ${ }^{3}$ Rehabilitation Medicine, Columbia University College of Physicians and \\ Surgeons, and ${ }^{4}$ Department of Biobehavioral Sciences, Columbia University Teachers College, New York, New York
}

Submitted 18 June 2004; accepted in final form 15 February 2005

\begin{abstract}
Zhong, Xu, H. John Hilton, Gregory J. Gates, Sanja Jelic, Yaakov Stern, Matthew N. Bartels, Ronald E. DeMeersman, and Robert C. Basner. Increased sympathetic and decreased parasympathetic cardiovascular modulation in normal humans with acute sleep deprivation. J Appl Physiol 98: 2024-2032, 2005. First published February 17, 2005; doi:10.1152/japplphysiol.00620.2004.-Cardiovascular autonomic modulation during $36 \mathrm{~h}$ of total sleep deprivation (SD) was assessed in 18 normal subjects (16 men, 2 women, $26.0 \pm 4.6 \mathrm{yr}$ old). ECG and continuous blood pressure (BP) from radial artery tonometry were obtained at 2100 on the first study night (baseline) and every subsequent $12 \mathrm{~h}$ of SD. Each measurement period included resting supine, seated, and seated performing computerized tasks and measured vigilance and executive function. Subjects were not supine in the periods between measurements. Spectral analysis of heart rate variability (HRV) and BP variability (BPV) was computed for cardiac parasympathetic modulation [high-frequency power (HF)], sympathetic modulation [low-frequency power (LF)], sympathovagal balance (LF/HF power of R-R variability), and BPV sympathetic modulation (at LF). All spectral data were expressed in normalized units [(total power of the components/total powervery $L F) \times 100$ ]. Spontaneous baroreflex sensitivity (BRS), based on systolic BP and pulse interval powers, was also measured. Supine and sitting, BPV LF was significantly increased from baseline at 12, 24, and $36 \mathrm{~h}$ of SD. Sitting, HRV LF was increased at 12 and $24 \mathrm{~h}$ of SD, HRV $\mathrm{HF}$ was decreased at $12 \mathrm{~h} \mathrm{SD}$, and HRV LF/HF power of R-R variability was increased at $12 \mathrm{~h}$ of SD. BRS was decreased at $24 \mathrm{~h}$ of SD supine and seated. During the simple reaction time task (vigilance testing), the significantly increased sympathetic and decreased parasympathetic cardiac modulation and BRS extended through $36 \mathrm{~h}$ of SD. In summary, acute SD was associated with increased sympathetic and decreased parasympathetic cardiovascular modulation and decreased BRS, most consistently in the seated position and during simple reaction-time testing.
\end{abstract}

baroreflex; sympathovagal balance

SLEEP DEPRIVATION (SD) has been associated with an increased incidence of adverse cardiovascular and metabolic disorders in humans $(9,27,33,47,52,53)$. Increased blood pressure (BP) $(23,33,40)$, heart rate (HR), and urine catecholamine levels have been associated with acute SD in normotensive subjects $(15,33,51)$.

In contrast, some investigators have reported no increase in resting plasma catecholamines, $\operatorname{HR}(14,23)$, or $\mathrm{BP}(33)$ after total SD (26), and muscle sympathetic nerve activity has been found to decrease in normal humans at rest after a night of total $\mathrm{SD}$ in two recent carefully controlled and monitored studies $(23,40)$. These latter studies, in finding elevated resting BP

Address for reprint requests and other correspondence: R. C. Basner, Division of Pulmonary, Allergy and Critical Care, Columbia Univ. College of Physicians \& Surgeons, 622 West 168th St., VC 12-206, New York, NY 10032. levels with unchanged vascular resistance (23) and decreased baroreflex sensitivity (BRS) after SD (40), did not rule out the possibility that cardiovascular autonomic modulation may be adversely affected by acute SD. Furthermore, these and other studies that have found no increase in sympathetic activity with SD have reported measurements made with the subjects remaining exclusively supine throughout the SD and testing period $(8,19,23,40)$. Similarly, although neurocognitive and vigilance demands may influence autonomic measurements during $\mathrm{SD}(3,9,50)$, there have been few prior attempts to systematically quantify autonomic function in association with vigilance and cognitive performance in a large cohort of normal subjects undergoing SD. No studies of acute SD have assessed spontaneous baroreflex activity in association with beat-to-beat heart and BP autonomic modulation in subjects not confined to the supine position.

The aims of the present study were therefore to investigate the hypotheses that, in young, healthy subjects undergoing total SD and not restricted to the supine position, l) significant increases in sympathetic and decreases in parasympathetic cardiovascular modulation would be found in association with a decrease in BRS and 2) these autonomic changes would be potentiated as a function of SD when subjects were engaged in cognitively demanding tasks.

\section{MATERIALS AND METHODS}

\section{Subjects}

Subjects between 18 and $40 \mathrm{yr}$ of age of both genders were recruited by advertisement. Twenty-one subjects ( 2 women, 19 men), ages $26.1 \pm 4.4 \mathrm{yr}$, were enrolled; all completed the protocol. All enrolled subjects were without acute or chronic medical disorders and were of normal body habitus. All subjects underwent a detailed medical history and physical examination by the physician investigators. Subjects with a history of seizure disorder, with acute or chronic sleep disorders including long and short sleepers and shift workers, subjects receiving any medications other than oral contraceptives, smokers, and daily ethanol users were excluded. All enrolled subjects passed substance abuse screening tests. Screening neuropsychological tests including the SCID-NP DSM-IV (nonpatient version) were used to ensure that subjects did not have any current Axis I psychiatric condition, including psychosis, major depression, bipolar disorder, or dysthymia. Sleep logs kept for 2 wk preceding the laboratory phase of the study were used to screen for a normal sleep pattern before the SD phase; Epworth Sleepiness scales were used to screen for baseline excessive subjective sleepiness (22). All subjects gave written, informed consent in accordance with the Columbia University College

The costs of publication of this article were defrayed in part by the payment of page charges. The article must therefore be hereby marked "advertisement" in accordance with 18 U.S.C. Section 1734 solely to indicate this fact. 
of Physicians and Surgeons institutional review board before participating in this study. All subjects received financial compensation for participating in this study. This study was supported by the Institutional Review Board of the Columbia Unversity College of Physicians and Surgeons.

\section{Measurements and Signal Processing}

Subjects were monitored with polysomnography (central and occipital referential electroencephalography, right and left electrooculography, and submental electromyography) to assure maintenance of the awake state when they were in the sleep bedrooms. During periods of cardiovascular recording, HR was assessed by electrocardiogram obtained from precordial surface electrodes using a V5 configuration. Continuous beat-to-beat BP was recorded from the radial artery by applanation tonometer using a noninvasive wrist oscillometric device (model 7000, Colin Medical Instruments, San Antonio, TX) (2, 21). The beat-to-beat BP was calibrated by brachial cuff BP before each measuring period. The signal was sampled at $200 \mathrm{~Hz} /$ channel with an analog-to-digital converter (DAQ-700, National Instruments, Austin,
TX) as per the limits of the collection system and in accordance with previous studies in our laboratory $(2,10-12)$ and Task Force guidelines for HR variability (HRV) measurements and interpretation (49). Signals were not filtered during collection. Respiratory movements of the rib cage and abdomen were recorded with piezo sensor bands. Respiratory flow was recorded by a heat-sensitive nasal-oral thermistor. All physiological data were collected and stored synchronously on an Embla signal recording system with Somnologica Windows NT Software (Flaga Medical Devices) and were analyzed offline. Polygraphs from a representative subject are shown in Fig. 1.

\section{Continuous Recognition Tests}

Three continuous performance tests were used as cognitive tasks: a simple detection reaction time and two go/no go choice reaction time tasks, one based on shape discrimination (go/no go) and the other based on a two-back letter sequence comparison (2-back task). The cognitive paradigms were designed to assess cognitive functions that are affected by SD and that are key to the performance of many complex tasks in which an average human might engage during daily

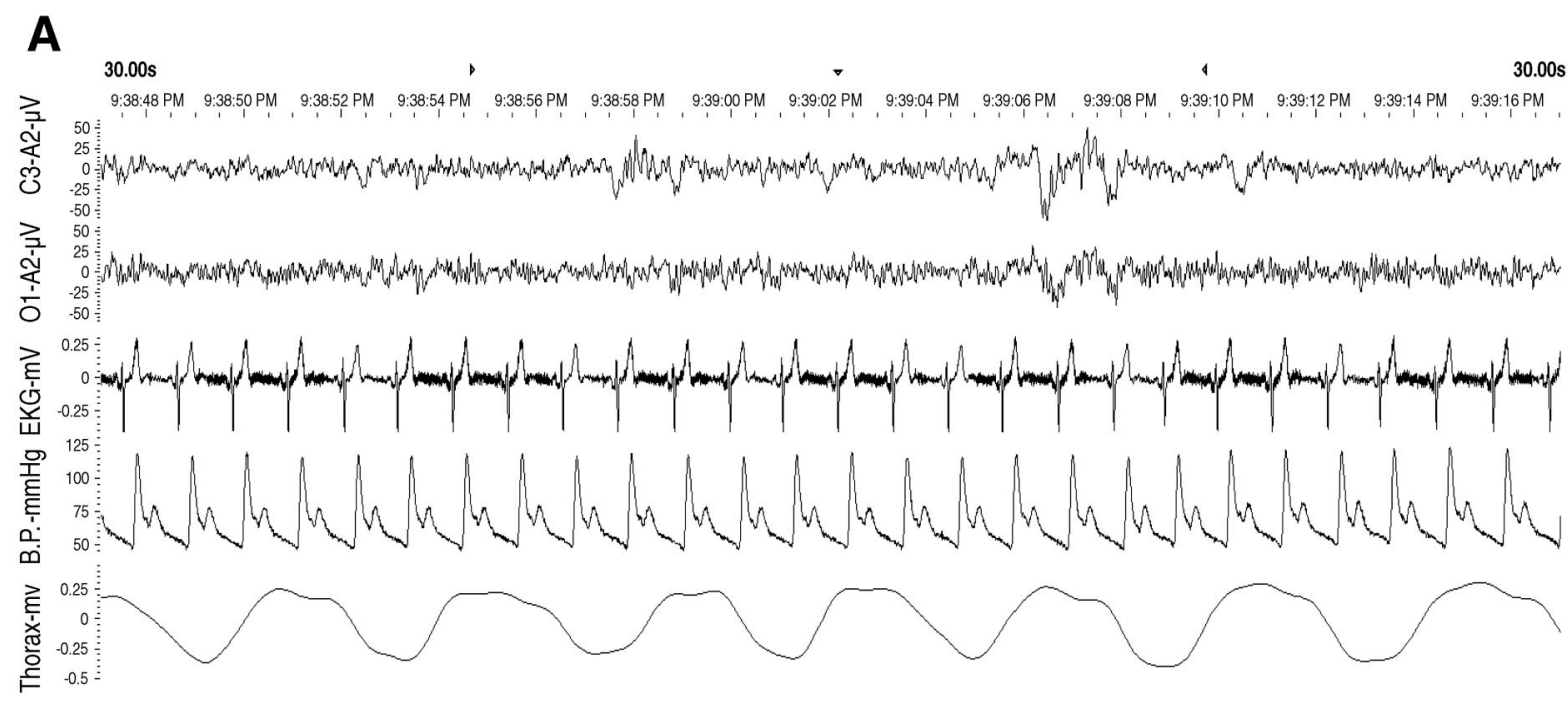

B

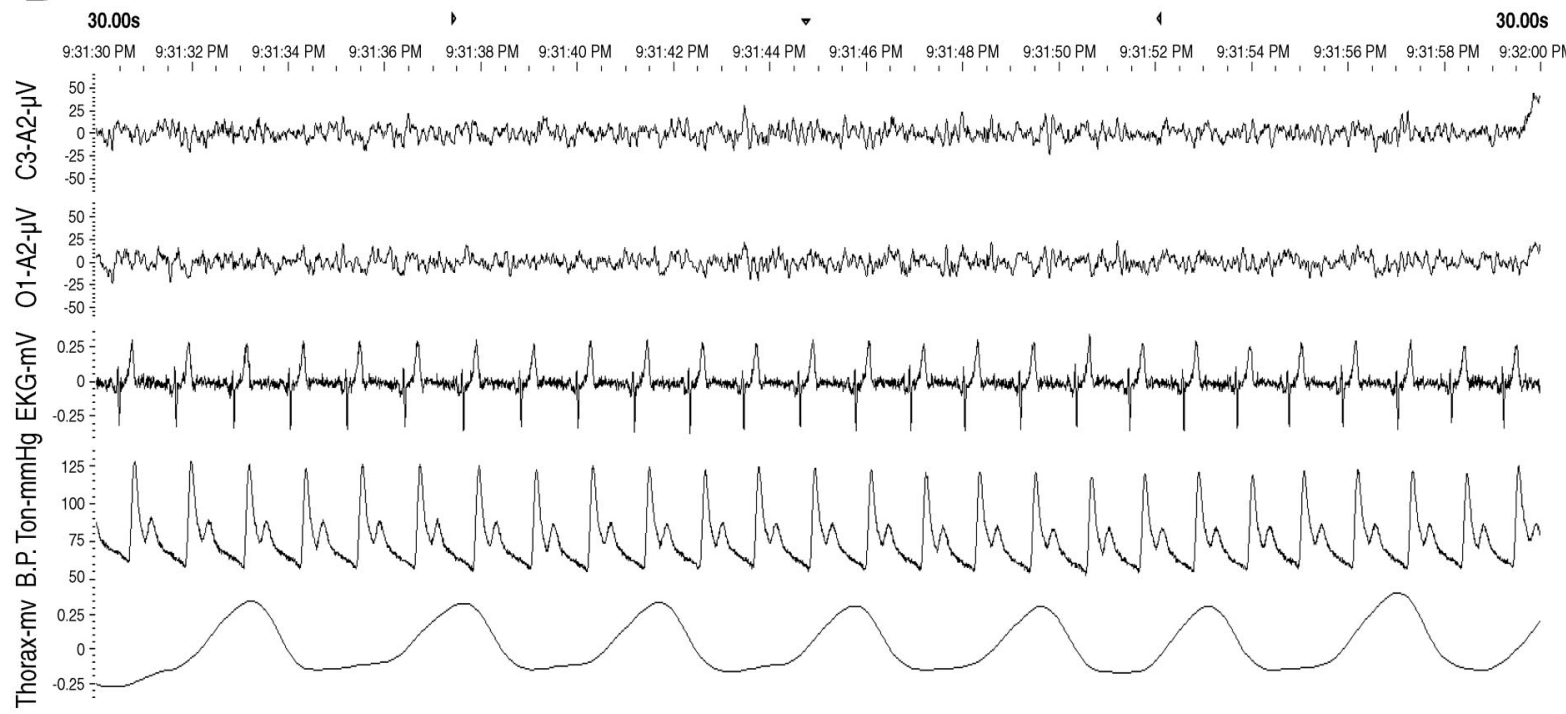

Fig. 1. Thirty seconds of continuous polygraphic tracings of a representative subject seated at baseline $(A)$ and at $24 \mathrm{~h}$ of sleep deprivation $(B)$. Depicted are awake electroencephalogram (C3-A2 and O1-A2, central and occipital referential derivations), precordial electrocardiogram (EKG), radial artery blood pressure (BP), and thoracic respiratory effort (Thorax). Other physiological measures are not shown for space considerations. 
behavioral functioning $(13,54)$. The simple detection reaction time task calls on basic vigilance. The shape go/no go task maintains the same vigilance component but also adds a memory component to hold the identity of the shape go and no go stimuli and a decision component. The 2-back task maintains vigilance, memory, and decision components but also requires an executive-attentional component to continually update two items held in memory with every successive trial. The ordered nature of cognitive load in these three tasks, although maintaining the same test structure, introduces the factor of increasing cognitive demand. Administration of all tasks was controlled, and behavioral data collected, using Psyscope software running on a Macintosh Powerbook computer. These tasks were administered with the subject in the sitting position and with cardiovascular data being collected throughout the task. The subject had her/his dominant hand free to easily press the keyboard for the response, with the nondominant arm held in a steady position at heart level with the arterial tonometer attached for cardiovascular data collection. Tasks were administered at baseline (2100) and every $12 \mathrm{~h}$ thereafter throughout the SD period.

All cognitive tasks were $10 \mathrm{~min}$ in duration to allow valid cognitive assessment as well as stable cardiovascular data collection. The participant was taught the tasks before the beginning of the laboratory trial by the investigators. A technician was always present to supervise the performance of these tasks, which are computerized and generally involve no specific prompting by the investigator, as well as to ensure that the cardiovascular data were collected without movement artifact. Audible tones were incorporated into the cognitive tasks to signal nonresponses as reminders to both the subject and the research assistant that responses have not been made. At these times, the technologist was instructed to prompt the patient to stay awake.

\section{$H R V$ and BP Variability}

The digitized unfiltered ECG and arterial pressure waveforms were analyzed using customized LabView software to obtain spectral components of HRV and BP variability (BPV). Before analyses, the ECG signal was inspected for artifact correction and rejection following established procedures $(10,49)$. All data acquisition and postacquisition analyses were carried out in accordance with established standards, including those put forth by the Task Force on HRV interpretation $(43,49)$. The R-wave peaks and BP peaks were detected via an established peak-detection algorithm (10-12).

Spectral components for HRV and BPV analyses were expressed as both absolute units and normalized units, calculated as [absolute power of the components/(total power - very low-frequency power)] $\times 100(16,45)$. Power in the very low-frequency $(\mathrm{LF} ;<0.04$ $\mathrm{Hz}$ ), LF (0.04-0.15 Hz), and high-frequency (HF; $>0.15$ to $0.40 \mathrm{~Hz}$ ) range was calculated for HRV. HF power of R-R variability (HRV $\mathrm{HF}$ ) is considered a function of cardiac parasympathetic nervous system activity to the heart (42). The LF component of R-R variability (HRV LF), although not modulated by a single arm of the autonomic nervous system (24), is considered normalized for total power as a representative index of sympathetic activity to the heart $(35,41,49)$. The LF-to-HF power ratio of R-R variability $\left(\mathrm{LF}_{\mathrm{R}-\mathrm{R}} / \mathrm{HF}_{\mathrm{R}-\mathrm{R}}\right)$ is considered an index of the balance of sympathovagal input to sinoatrial node activity and has been found to be representative of sympathetic to parasympathetic balance in both physiological and pathophysiological conditions $(34,38,41,42,49)$.

To define sympathetic modulation of BPV, beat-to-beat systolic BP (SBP) was analyzed for normalized LF modulation (BPV LF; $0.04-$ $0.15 \mathrm{~Hz}$ ); this activity appears to be specific for sympathetic modulation of the microcirculation without influence of the respiratory system $(4,29,41-43)$.

\section{BRS Assessment}

Spontaneous BRS assessment was carried out during the same epochs as the spectral analyses. Spontaneous BRS was assessed using the LF alpha index, calculated as the square root of the ratio of HRV LF to BPV LF $(44,56)$. Coherence between the SBP and pulse interval in the LF band (power of the LF of the cross spectrum/square root of the product of LF HRV and LF BPV) was always $>0.5(20,44)$.

All physiological data were analyzed over the last $5 \mathrm{~min}$ of artifact-free data for each condition (supine, sitting up, and sitting up during each cognitive test). Where 5 min of such continuous artifactfree data were not available, which was only rarely the case, we used the longest such continuous data period, with a minimum of 3 continuous min (49). For each variable, each period of data collection was averaged to yield a single value for each subject. The mean $r^{2}$ for the R-R intervals over each segment ranged from 0.024 to 0.079 , indicating no systematic linear trends to changes in the R-R intervals for these segments. Such analysis assumes, as well, stationarity of higher-order statistical moments.

\section{Protocol}

No caffeine or alcohol was allowed for the $48 \mathrm{~h}$ preceding the laboratory studies through the completion of the study. Enrolled subjects reported to the sleep laboratory at 0730 after obtaining their typical sleep at home the prior night. All subjects abstained from alcohol, caffeine, and other stimulants for $24 \mathrm{~h}$ before and during the study.

Each subject remained in the sleep lab from 1700 of day 1 through 0900 of day 3. All subjects had a dedicated bedroom in the sleep laboratory for the entire study. All physiological measurements were performed in the bedroom, which was kept at $22^{\circ} \mathrm{C}$ for the entire study period. Subjects were continuously monitored by video camera and polysomnography, except during short periods of ambulation every $2 \mathrm{~h}$ throughout the day or sitting in the monitoring control room with the sleep technician during nocturnal hours (when the sleep urge generally was particularly strong), when they were under direct visual surveillance by the technicians. Subjects displaying sleep onset either behaviorally or by electroencephalogram were immediately aroused and kept awake by verbal encouragement. Subjects were maintained at laboratory illumination of 100 lux. Caloric and fluid intake was standardized for all subjects based on estimated daily caloric and fluid needs. Snacks, however, were allowed ad libitum. Subjects took all their meals in the sleep laboratory. Subjects did not shower; they performed washing and toiletry as necessary throughout the protocol in the same washroom. Subjects were generally sitting or on their feet during periods between measurements; the supine position was avoided. When not engaged in any specific testing or tasks, subjects were allowed to read, watch video movies on a DVD player, play video games, do school or job-related work, including using the computer including the internet, and converse with the staff or visitors.

\section{Physiological and Cognitive Measurements}

Physiological and cognitive testing measurements were performed in the participant's bedroom in the sleep laboratory; measurements were made before meals. Measurements of HR, respiratory rate (RR), beat-to-beat $\mathrm{BP}$, and oxygen saturation of hemoglobin $\left(\mathrm{Sa}_{2}\right)$ were obtained at four points during the study: at 2100 on the first night of the study (baseline), 0900 and 2100 of the second day of study, and 0700 of the third day. Each of the measurement periods began with a 10 -min undisturbed supine period with the monitoring equipment in place. All data were then collected in the following order after the 10-min undisturbed supine period: $15 \mathrm{~min}$ undisturbed supine, $15 \mathrm{~min}$ undisturbed sitting-up, and $30 \mathrm{~min}$ of three consecutive cognitive testing while sitting up [simple reaction time testing (10 min), go/no go testing (10 $\mathrm{min})$, and 2-back task testing $(10 \mathrm{~min})]$.

\section{Data Analysis}

The outcome variables were each of the physiological variables described above. Generalized estimating equation (GEE) methods were used to examine the effect of SD at 12, 24, and $36 \mathrm{~h}$ after 
Table 1. Cognitive performance during sleep deprivation (all subjects)

\begin{tabular}{lcccc}
\hline \hline & Baseline & 12 -h SD & $24-\mathrm{h} \mathrm{SD}$ \\
\hline Median RT, ms & & & $36-\mathrm{h} \mathrm{SD}$ \\
SRT & $316.4 \pm 32.6$ & $405.8 \pm 84.1 \dagger$ & $391.4 \pm 90.3 \dagger$ & \\
GNG & $459.2 \pm 56.2$ & $595.6 \pm 204.8^{*}$ & $545.6 \pm 99.0 \dagger$ & \\
Back & $481.4 \pm 93.6$ & $615.8 \pm 155.4 \dagger$ & $707.4 \pm 226.3 \dagger$ & \\
Correct go responses, \% & & & $91.4 \pm 107.5 \dagger$ \\
GNG & $99.5 \pm 1.1$ & $95.5 \pm 8.1$ & $91.8 \pm 16.7$ & $852.4 \pm 328.6 \dagger$ \\
Back & $93.3 \pm 7.0$ & $87.9 \pm 9.1^{*}$ & $78.6 \pm 21.3^{*}$ & $82.9 \pm 9.5 \dagger$ \\
\hline
\end{tabular}

Values are means \pm SE. SD, sleep deprivation; RT, reaction time; SRT, simple RT; GNG, go/no go task; Back, 2-back task. $* P<0.05$ vs. baseline. $\dagger P \leq$ 0.001 vs. baseline.

baseline on the physiological data at each of the five positions (supine, seated, seated + simple reaction time, seated + shape go-no go reaction time, and seated +2 -back task). The GEE is a generalized linear model estimating method for longitudinal data in which the within-group correlation can be specified. It fits a population-averaged model. Thus the method accounted for the repeated measures obtained from each participant at different stages of SD. The GEE models assumed that the data were normally distributed with an exchangeable correlations structure $(31,55)$. SD was coded as a categorical variable. All analyses were done in STATA 8.0. Statistical significance was considered at the level of $P<0.05$.

To assess whether autonomic changes might be due to testing effect rather than to $\mathrm{SD}$, we also recruited six normal subjects ( 2 women, 4 men, ages $31.2 \pm 2.9 \mathrm{yr}$ ) to undergo similar testing without SD. These subjects were recruited during a period of normal sleep-wake cycles and slept at home rather than in the laboratory. They reported an average of $7.8 \pm 0.5 \mathrm{~h}$ of sleep on the 2 nights of sleep within the protocol time. They were studied at a similar but not duplicate circadian time as SD subjects; AM measurements were taken at 0900, i.e., generally $2 \mathrm{~h}$ later than the AM measurements in the SD subjects, and PM measurements were at 1700, i.e., generally $4 \mathrm{~h}$ earlier than SD PM measurements.

\section{RESULTS}

Three of the 21 subjects were excluded from final data analysis because of excessive movement artifact in their physiological signals, which precluded satisfactory analysis for all study periods. The remaining 18 subjects ( 2 women and 16 men), ages $19-36 \mathrm{yr}(26.0 \pm 4.6 \mathrm{yr})$ with an average body mass index of $23.4 \pm 2.9 \mathrm{~kg} / \mathrm{m}^{2}$, are reported here. Fifteen were Caucasian, and three were African-American. All sub- jects demonstrated a normal sleep pattern over the previous 2 wk as per their sleep diaries. The average nightly amount of sleep in this period was $8.0 \pm 0.8 \mathrm{~h}$. Mean Epworth Sleepiness Scale scores were $6.1 \pm 3.0$, which was in the normal range (22). Mean education for the group was $15.4 \pm 1.1 \mathrm{yr}$.

\section{Cognitive Performance Data}

SD was associated with an overall progressive decline in vigilance, as defined by simple reaction time latencies, and cognitive performance, as defined by percent correct responses on the cognitive tasks. These data are displayed in Table 1. The Epworth Sleepiness Scale scores increased from $6.1 \pm 3.0$ before SD, within normal range, to $17.7 \pm 5.4$, within the range associated with hypersomnia (22), at $36 \mathrm{~h}$ of SD.

\section{Resting Physiological Data During SD}

Supine, there were no significant differences in SBP, diastolic (DBP), or mean arterial BP (MAP) from non-SD baseline to any point of the SD. There was a significant decline in $\mathrm{HR}$ at 12 and $36 \mathrm{~h}$ of SD compared with baseline and a significant decline in RR at 12, 24, and $36 \mathrm{~h}$ of SD

There was no significant change in any parameter of normalized HRV with SD. There was, however, an increase in normalized LF modulation of BPV at 12, 24, and $36 \mathrm{~h}$ of SD compared with baseline. Spontaneous BRS significantly declined at $24 \mathrm{~h}$ of SD. Complete supine physiological data are presented in Table 2.

Seated, as with the supine position, there were no significant differences in SBP, DBP, or MAP from baseline to any point

Table 2. Supine physiological data (all subjects)

\begin{tabular}{|c|c|c|c|c|c|c|c|c|c|c|}
\hline & \multirow[b]{3}{*}{ Baseline } & \multicolumn{9}{|c|}{ Sleep Deprivation } \\
\hline & & \multicolumn{3}{|c|}{$12 \mathrm{~h}$} & \multicolumn{3}{|c|}{$24 \mathrm{~h}$} & \multicolumn{3}{|c|}{$36 \mathrm{~h}$} \\
\hline & & $\Delta$ & $\mathrm{CI}$ & $P$ & $\Delta$ & $\mathrm{CI}$ & $P$ & $\Delta$ & $\mathrm{CI}$ & $P$ \\
\hline $\mathrm{HR}$, beats/min & $62.1 \pm 9.0$ & $-3.94 *$ & $-6.46,-1.41$ & 0.002 & +0.54 & $-1.98,+3.05$ & 0.42 & $-5.19 *$ & $-7.71, \quad-2.67$ & $<0.001$ \\
\hline $\mathrm{RR}$, beats/min & $17.8 \pm 3.1$ & $-1.38 *$ & $-1.99,-0.78$ & $<0.001$ & $-0.77 *$ & $-1.38,-0.17$ & 0.012 & $-2.06^{*}$ & $-2.67, \quad-1.45$ & $<0.001$ \\
\hline $\mathrm{SBP}, \mathrm{mmHg}$ & $118.1 \pm 9.9$ & +3.52 & $-2.34,+9.50$ & 0.234 & +3.01 & $-2.95,+8.98$ & 0.32 & +4.78 & $-1.18,+10.75$ & 0.16 \\
\hline $\mathrm{DBP}, \mathrm{mmHg}$ & $60.8 \pm 8.4$ & +2.74 & $-1.55,+7.04$ & 0.21 & +1.61 & $-2.68,+5.90$ & 0.45 & +3.34 & $0.095,+7.54$ & 0.13 \\
\hline HRV LF(n) & $50.1 \pm 18.4$ & +3.09 & $-3.72,+9.89$ & 0.37 & +2.73 & $-4.07,+9.53$ & 0.43 & +4.21 & $-2.59,+11.01$ & 0.22 \\
\hline HRV HF(n) & $33.7 \pm 11.2$ & -0.5 .44 & $-6.05,+4.95$ & 0.85 & -0.474 & $-5.98,+5.03$ & 0.87 & -1.23 & $-6.73, \quad+4.28$ & 0.66 \\
\hline $\mathrm{LF}_{\mathrm{R}-\mathrm{R}} / \mathrm{HF}_{\mathrm{R}-\mathrm{R}}$ & $1.8 \pm 1.2$ & +0.11 & $-0.22,+0.44$ & 0.51 & +0.15 & $-0.19,+0.48$ & 0.39 & +0.17 & $-0.17, \quad+0.50$ & 0.33 \\
\hline BPV LF(n) & $63.2 \pm 16.48$ & $+9.24 *$ & $+1.00,+17.49$ & 0.028 & $+11.18 *$ & $+2.94,+19.43$ & 0.008 & $+12.50 *$ & $+4.26,+20.75$ & 0.003 \\
\hline BRS & $22.5 \pm 11.8$ & +1.05 & $-0.16, \quad 0.26$ & 0.65 & $-0.23 *$ & $-0.45,-0.02$ & 0.033 & -0.09 & $-0.30, \quad+0.12$ & 0.40 \\
\hline
\end{tabular}

Data are for all subjects, supine. Baseline data are means \pm SD. Sleep deprivation change $(\Delta)$ from baseline in heart rate (HR), respiratory rate (RR), systolic (SBP) and diastolic (DBP) blood pressure, normalized low-frequency power of HR variability [HRV LF (n)], normalized high-frequency power of HR variability [HRV HF(n)], sympathovagal balance [LF/HF power of R-R variability $\left.\left(\mathrm{LF}_{\mathrm{R}-\mathrm{R}} / \mathrm{HF}_{\mathrm{R}-\mathrm{R}}\right)\right]$ normalized low-frequency power of blood pressure variability [BPV $\mathrm{LF}(\mathrm{n})$ ], and spontaneous baroreflex sensitivity (BRS; given as the low-frequency component of the alpha index of BRS). CI, confidence intervals; $P, P$ value from generalized estimating equation (GEE) method. * Significant changes $(P<0.05)$. 
Table 3. Seated physiological data (all subjects)

\begin{tabular}{|c|c|c|c|c|c|c|c|c|c|c|}
\hline & \multirow[b]{3}{*}{ Baseline } & \multicolumn{9}{|c|}{ Sleep Deprivation } \\
\hline & & \multicolumn{3}{|c|}{$12 \mathrm{~h}$} & \multicolumn{3}{|c|}{$24 \mathrm{~h}$} & \multicolumn{3}{|c|}{$36 \mathrm{~h}$} \\
\hline & & $\Delta$ & $\mathrm{CI}$ & $P$ & $\Delta$ & $\mathrm{CI}$ & $P$ & $\Delta$ & $\mathrm{CI}$ & $P$ \\
\hline $\mathrm{HR}$, beats/min & $64.9 \pm 2.5$ & -0.82 & $-3.79,+2.16$ & 0.59 & $+3.11 *$ & $+0.13,+6.09$ & 0.04 & -2.21 & $-5.19,+0.77$ & 0.15 \\
\hline $\mathrm{RR}$, beats/min & $17.2 \pm 2.9$ & $-1.17 *$ & $-1.78,-0.55$ & $<0.001$ & -0.56 & $-1.17,-0.06$ & 0.08 & $-1.55^{*}$ & $-2.17,-0.94$ & $<0.001$ \\
\hline $\mathrm{SBP}, \mathrm{mmHg}$ & $119.5 \pm 14.0$ & -0.02 & $-6.80,+6.76$ & 0.99 & +5.08 & $-1.70,+11.85$ & 0.14 & -1.35 & $-8.13,+5.43$ & 0.69 \\
\hline $\mathrm{DBP}, \mathrm{mmHg}$ & $63.2 \pm 11.5$ & +2.13 & $-2.99,+7.26$ & 0.41 & -0.31 & $-5.43,+4.82$ & 0.91 & +0.49 & $-4.53,+5.62$ & 0.85 \\
\hline HRV LF(n) & $59.39 \pm 15.65$ & $+7.73 *$ & $+0.40,+15.06$ & 0.039 & $+7.54 *$ & $+0.22,+14.88$ & 0.044 & +6.61 & $-0.72,+13.94$ & 0.077 \\
\hline HRV HF(n) & $29.03 \pm 11.57$ & $-6.31^{*}$ & $-12.01,-0.62$ & 0.030 & -5.35 & $-11.05,+0.34$ & 0.066 & -5.57 & $-11.26,+0.12$ & 0.055 \\
\hline $\mathrm{LF}_{\mathrm{R}-\mathrm{R}} / \mathrm{HF}_{\mathrm{R}-\mathrm{R}}$ & $2.66 \pm 1.74$ & $+0.40 *$ & $+0.03,+0.76$ & 0.030 & +0.33 & $0.03,+0.70$ & 0.07 & $+0.36^{*}$ & $0.00,+0.72$ & 0.05 \\
\hline BPV LF (n) & $59.41 \pm 15.84$ & $+16.02 *$ & $+7.49,+24.56$ & $<0.001$ & $+15.43 *$ & $+6.89,+23.96$ & $<0.001$ & $+16.55^{*}$ & $+8.01,+25.09$ & $<0.001$ \\
\hline BRS & $20.1 \pm 8.8$ & -0.18 & $-0.42,+0.05$ & 0.129 & $-0.28 *$ & $-0.51,-0.04$ & 0.020 & -0.18 & $-0.42,+0.05$ & 0.13 \\
\hline
\end{tabular}

Baseline data are means \pm SD. Sleep deprivation change in seated physiological parameters. * Significant changes from baseline $(P<0.05)$.

in the $36 \mathrm{~h}$ of SD and a decline in RR at 12, 24, and $36 \mathrm{~h}$ of SD. However, autonomic perturbations associated with SD were more frequent than when the subjects were supine. There was a significant increase in HR at $24 \mathrm{~h}$ of SD compared with baseline. Normalized LF modulation of HRV increased significantly at 12 and $24 \mathrm{~h}$ of SD compared with baseline, in association with a significant decline in normalized HF modulation of HRV at $12 \mathrm{~h}$ of SD and a borderline significant decrease in normalized HF HRV $(P=0.055)$ at $36 \mathrm{~h}$ of SD. $\mathrm{HRV} \mathrm{LF}_{\mathrm{R}-\mathrm{R}} / \mathrm{HF}_{\mathrm{R}-\mathrm{R}}$ increased significantly at 12 and $36 \mathrm{~h}$ of SD. Seated normalized LF BPV was increased significantly throughout the SD periods, and BRS significantly declined at $24 \mathrm{~h}$ of SD; these changes were similar to those seen in the supine position. Complete seated physiological data are presented in Table 3.

\section{Physiological Data During SD With Cognitive Testing (All Measures Seated)}

Simple reaction time task. $\mathrm{HR}, \mathrm{SBP}, \mathrm{DBP}$, and MAP showed no significant change with SD, whereas RR significantly declined at 12 and $36 \mathrm{~h}$ of SD. Autonomic perturbations were more consistently found across the SD period when measured during this cognitive task than when measured with subjects at rest without testing: normalized $\mathrm{LF} H \mathrm{HRV}$ and $\mathrm{LF}_{\mathrm{R}-\mathrm{R}} / \mathrm{HF}_{\mathrm{R}-\mathrm{R}}$ increased significantly at 12,24 , and $36 \mathrm{~h}$ of SD, whereas normalized HF HRV significantly decreased at 12,24 , and $36 \mathrm{~h}$ of SD. BRS declined throughout the SD period when measured during the simple reaction time task in contrast to the decline in BRS seen only at $24 \mathrm{~h}$ of SD in the subjects when they were not performing cognitive tasks. Normalized LF BPV increased significantly throughout the SD period compared with baseline, as it did without performance of the simple reaction time task. These data are presented in Table 4.

Shape go/no go task. SBP, DBP, and MAP again showed no significant change from baseline with SD. There was a significant increase in HR at $24 \mathrm{~h}$ of SD only. There was a significant decline in RR throughout SD. Sympathetic perturbations were somewhat more consistently found across the SD period when measured during this cognitive task than when measured with subjects at rest without testing in that normalize LF HRV was increased significantly at 12 and $36 \mathrm{~h}$ of SD, with a borderline significant increase $(P=0.059)$ at $24 \mathrm{~h}$ of SD. There continued to be a consistent increase in normalized LF BPV across the SD period, whereas BRS declined significantly only at $24 \mathrm{~h}$ of $\mathrm{SD}$, as occurred in the subjects when they did not undergo cognitive testing. These data are presented in Table 5.

2-back task. HR, SBP, DBP, and MAP showed no significant change with SD. There was a significant decline in RR at 12 and $36 \mathrm{~h}$ of SD. Autonomic perturbations were less consistent than those seen without cognitive testing: the only significant changes were an increase in normalized LF HRV at $12 \mathrm{~h}$ of SD and an increase in normalized LF BPV at 12, 24, and $36 \mathrm{~h}$ of SD. BRS showed no significant change from baseline with SD. These data are given in Table 6.

There was no significant interaction between SD and performance on cognitive testing for the dependent physiological

Table 4. Seated physiological data during simple reaction time task (all subjects)

\begin{tabular}{|c|c|c|c|c|c|c|c|c|c|c|}
\hline & \multirow[b]{2}{*}{ Baseline } & \multicolumn{9}{|c|}{ Sleep Deprivation } \\
\hline & & $\Delta$ & $\mathrm{CI}$ & $P$ & $\Delta$ & $\mathrm{CI}$ & $P$ & $\Delta$ & $\mathrm{CI}$ & $P$ \\
\hline HR, beats/min & $64.9 \pm 7.8$ & -0.20 & $-3.25,+2.85$ & 0.90 & +2.92 & $-0.13,+5.97$ & 0.06 & +0.23 & $-2.82,+3.27$ & 0.89 \\
\hline $\mathrm{RR}$, beats/min & $17.3 \pm 3.0$ & $-1.17^{*}$ & $-1.83,-0.51$ & 0.001 & -0.61 & $-1.27,+0.05$ & 0.07 & $-1.72 *$ & $-2.38,-1.06$ & $<0.001$ \\
\hline $\mathrm{SBP}, \mathrm{mmHg}$ & $120.4 \pm 14.7$ & +1.41 & $-5.96,+8.80$ & 0.71 & +0.18 & $-7.20,+7.55$ & 0.96 & -1.19 & $-8.57+6.18$ & 0.75 \\
\hline $\mathrm{DBP}, \mathrm{mmHg}$ & $65.1 \pm 13.0$ & +0.91 & $-4.99,+6.81$ & 0.75 & -2.42 & $-8.32,+3.48$ & 0.42 & +1.27 & $-4.52,+7.18$ & 0.57 \\
\hline $\mathrm{LF}_{\mathrm{R}-\mathrm{R}} / \mathrm{HF}_{\mathrm{R}-\mathrm{R}}$ & $2.4 \pm 1.2$ & $+0.47^{*}$ & $+0.19,+0.74$ & 0.001 & $+0.59^{*}$ & $-0.31+0.85$ & $<0.001$ & $+0.63^{*}$ & $+0.35,+0.91$ & $<0.001$ \\
\hline BPV LF (n) & $57.9 \pm 19.2$ & $+19.49 *$ & $+12.54,+26.43$ & $<0.001$ & $+19.13^{*}$ & $+12.19,+26.08$ & $<0.001$ & $+20.45^{*}$ & $+13.50,+27.40$ & $<0.001$ \\
\hline BRS & $21.7 \pm 11.1$ & $-0.24 *$ & $-0.46,-0.02$ & 0.04 & $-0.27 *$ & $-0.49,-0.05$ & 0.02 & $-0.26^{*}$ & $-0.49,-0.04$ & 0.02 \\
\hline
\end{tabular}

Baseline values are means \pm SD. Sleep deprivation change in seated position during simple reaction time task. $*$ Significant changes from baseline $(P<0.05)$. 
Table 5. Seated physiological data during shape go/no go task (all subjects)

\begin{tabular}{|c|c|c|c|c|c|c|c|c|c|c|}
\hline & \multirow[b]{2}{*}{ Baseline } & \multicolumn{9}{|c|}{ Sleep Deprivation } \\
\hline & & $\Delta$ & $\mathrm{CI}$ & $P$ & $\Delta$ & CI & $P$ & $\Delta$ & $\mathrm{CI}$ & $P$ \\
\hline $\mathrm{HR}$, beats/min & $65.1 \pm 7.3$ & -0.79 & $-3.70,+2.09$ & 0.59 & $+3.40 *$ & $+0.57,+6.22$ & 0.02 & +0.78 & $-2.05,+3.61$ & 0.59 \\
\hline $\mathrm{RR}$, beats/min & $17.3 \pm 3.0$ & $-1.06^{*}$ & $-1.64,-0.47$ & $<0.001$ & $-0.62 *$ & $-1.20,-0.02$ & 0.04 & $-1.61^{*}$ & $-2.20,-1.02$ & $<0.001$ \\
\hline $\mathrm{SBP}, \mathrm{mmHg}$ & $118.0 \pm 14.0$ & +2.29 & $-5.94,+10.53$ & 0.59 & +4.87 & $-5.43,+10.76$ & 0.52 & +2.67 & $-5.43+10.76$ & 0.52 \\
\hline $\mathrm{DBP}, \mathrm{mmHg}$ & $64.1 \pm 10.3$ & +3.11 & $-3.22,+9.43$ & 0.34 & +0.02 & $-6.20,+6.24$ & 0.99 & +4.10 & $-2.11, \quad 10.32$ & 0.20 \\
\hline $\mathrm{LF}_{\mathrm{R}-\mathrm{R}} / \mathrm{HF}_{\mathrm{R}-\mathrm{R}}$ & $3.5 \pm 2.1$ & +0.30 & $-0.05,+0.65$ & 0.09 & +0.30 & $-0.05,+0.64$ & 0.09 & +0.33 & $-0.01,+0.67$ & 0.06 \\
\hline BPV LF (n) & $70.5 \pm 12.5$ & $+6.57 *$ & $+0.37,+12.77$ & 0.04 & +5.67 & $-0.40,+11.75$ & 0.07 & $+7.40^{*}$ & $+1.33,+13.48$ & 0.02 \\
\hline BRS & $18.6 \pm 7.2$ & -0.06 & $-0.26,+0.15$ & 0.60 & $-0.21^{*}$ & $-0.41,-0.01$ & 0.04 & -0.17 & $-0.37,+0.03$ & 0.09 \\
\hline
\end{tabular}

Baseline values are means \pm SD. Sleep deprivation change in seated position during shape go/no go task. *Significant changes from baseline $(P<0.05)$.

variables in the GEE. In a separate analysis, autonomic data periods were excluded because of nonresponsiveness or randomness of the efforts during testing. This occurred primarily during the 2-back task at 24 and $36 \mathrm{~h}$ of testing. These exclusions did not significantly affect the interaction as noted above.

There were no significant differences in any autonomic parameter among the three SD times, supine or seated; i.e., increasing time of SD did not significantly affect the changes in autonomic activity seen at $12 \mathrm{~h}$ of SD. There was no significant interaction between SD and position. Thus the overall effect of SD on physiological measures did not differ by testing positions. Spectral data results were similar for absolute and normalized units; only normalized data are therefore presented.

For control subjects, BP, HRV, and BRS were not significantly changed over the course of the four measurements, either supine or seated. Supine, there was an increase in HR of 5.63 beats/min [95\% confidence interval (CI): 1.28, 9.98] at $24 \mathrm{~h}(P=0.01)$ compared with baseline $(68.5 \pm 9.3$ beats/ min). RR decreased 1.5 breaths/min (95\% CI: $-2.74,-0.26)$ at $12 \mathrm{~h}(P=0.02)$ and 1.33 breaths $/ \mathrm{min}(95 \% \mathrm{CI}:-2.57$, $-0.10)$ at $36 \mathrm{~h}(P=0.03)$ compared with baseline $(18.3 \pm 3.6$ breaths/min). Normalized LF BPV significantly increased $11.33 \%$ (95\% CI: $4.58,18.07)$ at $24 \mathrm{~h}(P=0.001)$ and $13.16 \%$ (95\% CI: $6.42,19.91)$ at $36 \mathrm{~h}(P<0.001)$ compared with baseline $(60.15 \pm 17.86 \%)$. Seated, RR decreased 1 breath $/ \mathrm{min}$ (95\% CI: $-1.95,-0.05)$ at $36 \mathrm{~h}(P=0.04)$.

\section{DISCUSSION}

The present study assessed cardiovascular autonomic modulation in association with total SD in a relatively large group of normal young subjects and demonstrated the following novel findings: 1) acute SD was associated with increased sympathetic cardiac and BP modulation, decreased parasympathetic cardiac modulation, and decreased BRS; 2) these adverse effects of SD on cardiovascular autonomic modulation were seen as early as $12 \mathrm{~h}$ of SD, without progressive increase in the autonomic perturbation through 24 and $36 \mathrm{~h}$ of SD. These findings were in contrast to control subjects, who showed no changes in HRV or BRS parameters across a similar time period of measurements.

The present findings are in agreement with the autonomic findings of Tochikubo and colleagues (51), who measured increases in both SBP and HRV $\mathrm{LF}_{\mathrm{R}-\mathrm{R}} / \mathrm{HF}_{\mathrm{R}-\mathrm{R}}$ during normal upright activities in young men after sleep restriction, in concert with increased urinary excretion of norepinephrine. The present findings also extend recent work concerning SD and abnormal metabolic control, which found that sleep restriction over the course of 6 nights results in decreased glucose tolerance and increased sympathetic modulation as assessed by HRV analysis (47). The present finding of decreased BRS with SD also agrees with and extends the findings of Ogawa et al. (40), who found decreased BRS after 1 night of SD in normal subjects.

Table 6. Seated physiological data during 2-back task (all subjects)

\begin{tabular}{|c|c|c|c|c|c|c|c|c|c|c|}
\hline & \multirow[b]{2}{*}{ Baseline } & \multicolumn{9}{|c|}{ Sleep Deprivation } \\
\hline & & $\Delta$ & $\mathrm{CI}$ & $P$ & $\Delta$ & $\mathrm{CI}$ & $P$ & $\Delta$ & CI & $P$ \\
\hline HR, beats/min & $66.5 \pm 8.1$ & +0.68 & $-2.84,+4.20$ & 0.70 & +1.85 & $-1.59,+5.30$ & 0.29 & -2.24 & $-5.69,+1.21$ & 0.20 \\
\hline $\mathrm{RR}$, beats/min & $17.2 \pm 2.9$ & $-1.06^{*}$ & $-1.69-0.42$ & 0.001 & -0.50 & $-1.14,+0.14$ & 0.12 & $-1.61 *$ & $-2.25,-0.98$ & $<0.001$ \\
\hline $\mathrm{SBP}, \mathrm{mmHg}$ & $118.3 \pm 17.0$ & +2.64 & $-6.04,+11.33$ & 0.55 & +1.78 & $-6.74+10.31$ & 0.68 & +1.44 & $-7.09+9.96$ & 0.74 \\
\hline $\mathrm{DBP}, \mathrm{mmHg}$ & $64.6 \pm 13.4$ & +2.23 & $-3.99,+8.45$ & 0.48 & -2.18 & $-8.29,+3.93$ & 0.48 & +1.21 & $-4.89,+7.33$ & 0.70 \\
\hline $\mathrm{LF}_{\mathrm{R}-\mathrm{R}} / \mathrm{HF}_{\mathrm{R}-\mathrm{R}}$ & $3.3 \pm 1.6$ & +0.33 & $-0.02,+0.68$ & 0.07 & +0.27 & $-0.07,+0.61$ & 0.13 & +0.32 & $-0.03,+0.66$ & 0.07 \\
\hline BPV LF (n) & $67.0 \pm 4.80$ & +6.18 & $-0.38,+12.73$ & 0.07 & $+7.50 *$ & $+1.08,+13.93$ & 0.02 & $+8.99 *$ & $+2.57,+15.42$ & 0.006 \\
\hline BRS & $17.2 \pm 5.5$ & +0.06 & $-0.17,+0.29$ & 0.63 & -0.18 & $-0.41,+0.05$ & 0.13 & +0.01 & $-0.22,+0.24$ & 0.94 \\
\hline
\end{tabular}

Baseline data are means \pm SD. Sleep deprivation change in seated position during 2-back task. *Significant changes from baseline $(P<0.05)$. 
In contrast, Chen (8) observed that $30 \mathrm{~h}$ of sleep loss in 15 healthy young men was associated with decreased HR and decreased resting plasma norepinephrine and epinephrine levels. Kato and colleagues (23) found in eight subjects that, whereas supine resting mean BP was higher, muscle sympathetic nerve activity was lower after a night of acute SD compared with a measurements after 1 night of normal sleep. $\mathrm{BP}, \mathrm{HR}$, and muscle sympathetic nerve activity were not consistently influenced by cognitive and physiological stressors after SD in that study, similar to the present findings. Similarly, Ogawa and colleagues (40) found that 1 night of nocturnal SD resulted in decreased muscle sympathetic nerve activity in a small group of young male subjects. Holmes and colleagues (19) studied 12 young subjects (men and women) over a 30-h recumbent awake period and found that, compared with a separate recumbent 6-h awake period, HR was decreased, as was $\beta$-adrenergic sympathetic activity (measured as preejection period via impedance cardiography), after the $30 \mathrm{~h}$ of awake time. Major methodological differences exist among these noted SD protocols and the present study: in particular, the fact that the recumbent position was maintained throughout the SD and data measurement period in the studies that found generally decreased sympathetic activity. In contrast, SD studies that monitor autonomic activity in the nonrecumbent individual, including the present study, appear to be more likely to find increased measures of sympathetic activity as a function of sleep restriction. It is emphasized, however, that the present study was designed only to be able to specifically test the physiological parameters during specific supine and seated testing periods, rather than throughout the SD period, and so does not directly address the question as to what overall effect position may have during progressive SD

Extensive data from our laboratory and others' have validated the scientific and practical utilization of spectral analysis of $\mathrm{HRV}$ and BPV as noninvasive measures of autonomic modulation under steady-state and non-steady-state conditions (1, 4, 10-12, 17, 25, 29, 34, 36, 39, 41-43, 46, 49), including during SD $(6,51)$. We note, however, that the LF alpha index methodology to assess BRS is only one method of assessing spontaneous baroreflex function and cannot by itself account for other influences, such as respiratory and other vagal input, chemoreceptor reflexes, nor discriminate between negative and positive feedback effects (44). Furthermore, the use of only the alpha index for the LF component as an assessment of BRS is not necessarily representative of BRS in relation to overall autonomic modulation; Merritt and colleagues (37) have shown in a group of elderly African Americans that computed alpha indexes of LF and HF power may have divergent correlations with normalized HF HRV. On the other hand, Zollei and colleagues (56) demonstrated good correlation in normal subjects between LF alpha index and both increased and decreased BP sequences and R-R interval changes in the same direction. Decreased BRS in the present study may represent central inhibitory modulation of baroreflex response with SD, analogous to that seen with alerting or arousal responses and opposite to that seen during quiet sleep (30). Such a mechanism might be, in turn, permissive for increased sympathetic to parasympathetic balance in the modulation of $\mathrm{HRV}$ and BPV, as found in the present study.

Spectral measures of HRV and BPV, as well as BRS, have demonstrated clinical significance. Changes in HRV and BPV similar to those found in the present study have been associated with poor cardiovascular prognosis in patients with cardiovascular disease (49), although increased normalized HF HRV has also been recently found to be associated with increased mortality after myocardial infarction (48). Increased LF HRV and decreased HF HRV, as found in our SD subjects, has been demonstrated to discriminate patients who were recently postmyocardial infarction from healthy subjects (32). Blunted BRS and impaired cardiovascular variability, common to cardiovascular disease states, are predictive of impaired cardiovascular outcome in patients with coronary artery disease and heart failure $(28,30)$.

Cardiovascular autonomic modulation during cognitively demanding tasks under conditions of SD has been rarely assessed in humans, and then only in small groups of subjects $(3,23)$. We did not find a statistically significant interaction between cognitive testing and SD regarding autonomic modulation in the overall GEE analysis nor was the level of performance on these cognitive tasks specifically correlated with autonomic changes. Furthermore, the changes with cognitive test perfomance were inconsistent, particularly with the more demanding tasks, possibly due to increased variability of responses as the tasks became more difficult. It is also of interest that we did not find consistent changes in HR or BP in association with decreased BRS with SD, with or without the cognitive task stressors. It may be that the study design, including the tasks themselves, was not sensitive enough to find such changes. Overall, these results demonstrate that the major effect of changes in autonomic parameters occurred as a function of SD and not additional cognitive testing and stress in the present study. However, the combination of SD and the simple reaction time testing did produce more consistently perturbed sympathovagal balance and BRS throughout the $36 \mathrm{~h}$ of SD compared with SD measurements without performance of the simple reaction time test and cognitive task performance alone, such that the possibility of an interaction between cognitive stress and SD-associated autonomic perturbations may merit further investigation.

BRS was decreased only at $24 \mathrm{~h}$ of SD without cognitive testing, and normalized LF HRV seated was similarly increased at 12 and 24 but not at $36 \mathrm{~h}$ of SD, raisng the possibility that a recovery from autonomic perturbtion may occur as SD progresses through $36 \mathrm{~h}$. However, the decrease in LF BPV occurred throughout the SD period beginning at $12 \mathrm{~h}$, and the integrated HRV measure $H R V L_{R-R} / H_{R-R}$ was increased at 12 and $36 \mathrm{~h}$ of $\mathrm{SD}$, suggesting that no consistent recovery of autonomic function occurred as SD progressed in the present study.

RR generally decreased with SD in our subjects, raising the concern that this change could have affected the spectral analyses of HRV. The small respiratory change did not, however, extend to the LF region at any time during baseline or SD. Furthermore, when adjusted for RR in the GEE, no significant differences in the effect of SD on autonomic findings were seen. Therefore, the small respiratory change from baseline through SD did not appear to explain the spectral changes found (5). However, we did not measure tidal volume changes in these subjects and cannot completely rule out a respiratory effect on these measures (2).

There is significant evidence to suggest that autonomic parameters in this study were primarily influenced by SD rather 
than circadian time, in contrast to the findings of Burgess and colleagues (6) regarding parasympathetic modulation in supine subjects during SD. Most of the autonomic changes in the present study were present in the AM and PM during SD, particularly during the vigilance task. Furthermore, control subjects generally did not show circadian variation in the major parameters, thus arguing that the major effects here were SD related rather than a circadian phenomenon. Nevertheless, circadian interaction with SD cannot be ruled out in these data. In particular, BRS declined significantly only from baseline PM to SD PM measurements in the subjects when they were not engaged in cognitive tasks. Similarly, a circadian effect may have been present in RR, which was most consistently lowest in AM measurements both in SD and control subjects. Aside from circadian effect, the testing procedure itself may have contributed to the LF BPV findings during SD, since control subjects showed an increase in LF BPV at 24 and $36 \mathrm{~h}$ supine and at $36 \mathrm{~h}$ seated.

In summary, the present data suggest that normal humans are vulnerable to a cohesive perturbation in autonomic cardiovascular modulation after $12 \mathrm{~h}$ of nocturnal SD, when they are not restricted to the supine position, and that this autonomic perturbation does not consistently extend through $36 \mathrm{~h}$ of SD. The clinical significance of such autonomic perturbation associated with acute SD in healthy, young subjects, as well as the extent and clinical significance of autonomic perturbations associated with SD in older subjects and those with cardiovascular disorders, remains to be investigated.

\section{ACKNOWLEDGMENTS}

The authors gratefully acknowledge the statistical support of Dr. Shing Lee in the Department of Biostatistics, Columbia University College of Physicians and Surgeons.

This work was presented in part at the Associated Professional Sleep Societies Annual Meeting in Philadelphia in June 2004.

\section{GRANTS}

This work was supported in part by Defense Advanced Research Projects Agency Grant DAAD 19-02-01-01147 and is approved for public release, distribution unlimited. X. Zhong was a visiting scholar from Peking Union Medical College Hospital, Beijing 100730, China, supported by a Wu Fellowship of the Sino-American Medical Fund of the College of Physicians and Surgeons of Columbia University.

\section{REFERENCES}

1. Bartels MN, Jelic S, Ngai P, Basner RC, and DeMeersman RE. High-frequency modulation of heart rate variability during exercise in patients with COPD. Chest 124: 863-869, 2003.

2. Bartels MN, Jelic S, Ngai P, Gates G, Newandee D, Reisman SS, Basner RC, and DeMeersman RE. The effect of ventilation on spectral analysis of heart rate and blood pressure variability during exercise. Respir Physiol Neurobiol 144: 91-98, 2004.

3. Benschop RJ, Nijkamp FP, Ballieux RE, and Heijnen CJ. The effects of $\beta$-adrenoceptor stimulation on adhesion of human natural killer cells to cultured endothelium. Br J Pharmacol 113: 1311-1316, 1994.

4. Bernardi L, Hayoz D, Wenzel R, Passino C, Calciati A, Weber R, and Noll G. Synchronous and baroreceptor-sensitive oscillations in skin microcirculation: evidence for central autonomic control. Am J Physiol Heart Circ Physiol 273: H1867-H1878, 1997.

5. Brown TE, Beightol LA, Koh J, and Eckberg DL. Important influence of respiration on human R-R interval power spectra is largely ignored. J Appl Physiol 75: 2310-2317, 1993.

6. Burgess HJ, Trinder J, Kim Y, and Luke D. Sleep and circadian influences on cardiac autonomic nervous system activity. Am J Physiol Heart Circ Physiol 273: H1761-H1768, 1997.
7. Chen CH, Ting CT, Nussbacher A, Nevo E, Kass DA, Pak P, Wang SP, Chang MS, and Yin FCP. Validation of carotid artery tonometer as a means of estimating augmentation index of ascending aortic pressure. Hypertension 27: 168-175, 1996.

8. Chen HI. Effects of 30-h sleep loss on cardiorespiratory functions at rest and in exercise. Med Sci Sports Exerc 23: 193-198, 1991.

9. Cohn JN, Finkelstein S, McVeigh G, Morgan D, LeMay L, Robinson $\mathbf{J}$, and Mock J. Non-invasive pulse wave analysis for the detection of arterial vascular disease. Hypertension 26:503-508, 1995.

10. De Meersman RE, Reisman SS, Daum M, Zorowitz R, Leifer M, and Findley T. Influence of respiration on metabolic, hemodynamic, psychometric, and R-R interval power spectral parameters. Am J Physiol Heart Circ Physiol 269: H1437-H1440, 1995.

11. De Meersman RE, Zion AS, Teitelbaum S, Weir JP, Lieberman J, and Downey J. Deriving respiration from pulse wave: a new signal-processing technique. Am J Physiol Heart Circ Physiol 270: H1672-H1675, 1996.

12. De Meersman RE, Zion AS, Weir JP, Lieberman JS, and Downey JA. Mechanoreceptors and autonomic responses to movement in humans. Clin Auton Res 8: 201-205, 1998.

13. Doran SM, Van Dongen HP, and Dinges DF. Sustained attention performance during sleep deprivation: evidence of state instability. Arch Ital Biol 139: 253-267, 2001.

14. Fiorica V, Higgins EA, Iampietro PF, Lategola MT, and Davis AW. Physiological responses of men during sleep deprivation. J Appl Physiol 24: 167-176, 1968.

15. Froberg JE, Karlsson CG, Levi L, and Lidberg L. Circadian variations in performance, psychological ratings, catecholamine excretion, and diuresis during prolonged sleep deprivation. Int J Psychobiol 2: 23-36, 1972.

16. Goldberger JJ. Sympatho-vagal balance: how should we measure it? Am J Physiol Heart Circ Physiol 276: H1273-H1280, 1999.

17. Grimm D, De Meersman R, Almenoff PL, Spungen AM, and Bauman WA. Sympatho-vagal balance of the heart in subjects with spinal cord injury. Am J Physiol Heart Circ Physiol 272: H835-H842, 1997.

18. Harrison $\mathbf{Y}$ and Horne JA. The impact of sleep deprivation on decision making: a review. J Exp Psychol Appl 6: 236-249, 2000.

19. Holmes AL, Burgess HJ, and Dawson D. Effects of sleep pressure on endogenous cardiac autonomic activity and body temperature. $J$ Appl Physiol 92: 2578-2584, 2002.

20. Hughson RL, Quintin L, Annat G, Yamamoto Y, and Gharib C. Spontaneous baroreflex by sequence and power spectral methods in humans. Clin Physiol 13: 663-676, 1993.

21. Jelic S, Bartels MN, Mateika JH, Ngai P, DeMeersman RE, and Basner RC. Arterial stiffness increases during obstructive sleep apneas. Sleep 25: 850-855, 2002.

22. Johns MW. A new method for measuring daytime sleepiness: the Epworth Sleepiness Scale. Sleep 14: 540-545, 1991.

23. Kato M, Phillips BG, Sigurdsson G, Narkiewicz K, Pesek CA, and Somers VK. Effects of sleep deprivation on neural circulatory control. Hypertension 35: 1173-1175, 2000.

24. Kingwell BA, Thompson JM, Kaye DM, McPherson GA, Jennings GL, and Esler MD. Heart rate spectral analysis, cardiac norepinephrine spillover, and muscle sympathetic nerve activity during human sympathetic nervous activation and failure. Circulation 90: 234-240, 1994.

25. Kohara K, Nishida W, Maguchi M, and Hiwada K. Autonomic nervous function in non-dipper essential hypertensive subjects. Evaluation by power spectral analysis of heart rate variability. Hypertension 26: $808-$ 820, 1995.

26. Kollar EJ, Slater GR, Palmer JO, Doctor RF, and Mandell AJ. Stress in subjects undergoing sleep deprivation. Psychosom Med 28: 101-113, 1966.

27. Krachman SL, D'Alonzo GE, and Criner GJ. Sleep in the intensive care unit. Chest 107: 1713-1720, 1995.

28. La Rovere MT, Bigger JT, Marcus FI, Mortora A, and Schwartz PJ. Baroreflex sensitivity and heart rate variability in prediction of total cardiac mortality after myocardial infarction. Lancet 351: 478-484, 1998.

29. Laitinen T, Hartikainen J, Niskanen L, Geelen G, and Länsimies E. Sympatho-vagal balance is major determinant of short-term blood pressure variability in healthy subjects. Am J Physiol Heart Circ Physiol 276: H1245-H1252, 1999.

30. Lanfranchini PA and Somers VK. Arterial baroreflex function and cardiovascular variability: interactions and implications. Am J Physiol Regul Integr Comp Physiol 283: R815-R826, 2002. 
31. Liang KY and Zeger SL. Longitudinal data analysis using generalized linear models. Biometrika 73: 13-22, 1986.

32. Lombardi F, Sandrone G, Mortara A, La Rovere MT, Colombo E, Guzzetti S, and Malliani A. Circadian variation of spectral indices of heart rate variability after myocardial infarction. Am Heart J 123: $1521-$ 1529, 1992.

33. Lusardi P, Mugellini A, Preti P, Zoppi A, Derosa G, and Fogari R. Effects of a restricted sleep regimen on ambulatory blood pressure monitoring in normotensive subjects. Am J Hypertens 9: 503-505, 1996.

34. Malfatto G, Facchini M, Sala L, Branzi G, Bragato R, and Leonetti G. Effects of cardiac rehabilitation and $\beta$-blocker therapy on heart rate variability after first acute myocardial infarction. Am J Cardiol 81: 834-840, 1998.

35. Malliani A, Pagani M, Lombardi F, and Cerutti S. Cardiovascular neural regulation explored in the frequency domain. Circulation 84: 482-492, 1991.

36. Mancia G. Blood pressure variability: mechanisms and clinical significance. J Cardiovasc Pharmacol 16: 1-6, 1990.

37. Merritt MM, Sollers JJ III, Evans MK, Zonderman AB, and Thayer JF. Relationships among spectral measures of baroreflex sensitivity and indices of cardiac vagal control. Biomed Sci Instrum 39: 193-198, 2003.

38. Montano N, Ruscone TG, Porta A, Lombardi F, Pagani M, and Malliani A. Power spectrum analysis of heart rate variability to assess the changes in sympatho-vagal balance during graded orthostatic tilt. Circulation 90: 1826-1831, 1994.

39. Nakamura Y, Yamamoto Y, and Muraoka I. Autonomic control of heart rate during physical exercise and fractal dimension of heart rate variability. J Appl Physiol 74: 875-881, 1993.

40. Ogawa Y, Kanbayashi T, Saito Y, Tahahashi Y, Kitajima T, Tahahashi K, Hishikawa Y, and Shimizu T. Total sleep deprivation elevates blood pressure through arterial baroreflex resetting: a study with microneurographic technique. Sleep 26: 986-989, 2003.

41. Pagani M, Lombardi F, Guzzetti S, Rimoldi O, Furlan R, Pizzinelli P, Sandrone G, Malfatto G, Dell'Orto S, and Piccaluga E. Power spectral analysis of heart rate and arterial pressure variabilities as a marker of sympatho-vagal interaction in man and conscious dog. Circ Res 59: 178-193, 1986.

42. Pagani M, Malfatto G, Pierini S, Casati R, Masu AM, Poli M, Guzzetti S, Lombardi F, Cerutti S, and Maliani A. Spectral analysis of heart rate variability in the assessment of autonomic diabetic neuropathy. J Auton Nerv Syst 23: 143-153, 1988.

43. Parati G, Saul JP, Di Rienzo M, and Mancia G. Spectral analysis of blood pressure and heart rate variability in evaluating cardiovascular regulation: a critical appraisal. Hypertension 25: 1276-1286, 1995.
44. Persson PB, DiRienzo M, Castiglione P, Cerutti C, Pagani M, Honzikova N, Akselrod S, and Parati G. Time versus frequency domain techniques for assessing baroreflex sensitivity. J Hypertens 19: 16991705, 2001.

45. Rimoldi O, Furlan R, Pagani MR, Piazza S, Guazzi M, Pagani M, and Malliani A. Analysis of neural mechanisms accompanying different intensities of dynamic exercise. Chest 101, Suppl 5: 226S-230S, 1992.

46. Saul JP, Berger RD, Albrecht P, Stein SP, Chen MH, and Cohen RJ. Transfer function analysis of the circulation: unique insights into cardiovascular regulation. Am J Physiol Heart Circ Physiol 261: H1231-H1245, 1991.

47. Spiegel K, Leproult R, and Van Cauter E. Impact of sleep debt on metabolic and endocrine function. Lancet 354: 1435-1439, 1999.

48. Stein PK, Domitrovich PP, Kleiger RE, and CAST Investigators. Including patients with diabetes mellitus or coronary artery bypass grafting decreases the association between heart rate variability and mortality after myocardial infarction. Am Heart J 147: 309-316, 2004.

49. Task Force of the European Society of Cardiology, and the North American Society of Pacing and Electrophysiology. Heart rate variability: standards of measurements, physiological interpretation, and clinical use. Circulation 93: 1043-1065, 1996.

50. Thomas M, Sing H, Belenky G, Holcomb H, Mayberg H, Dannals R, Wagner HJR, Thorne D, Popp K, Rowland L, Welsh A, Balwinski S, and Redmond D. Neural basis of alertness and cognitive performance impairments during sleepiness. I. Effects of 24 hours of sleep deprivation on waking human regional brain activity. J Sleep Res 9: 335-352, 2000.

51. Tochikubo O, Ikeda A, Miyajima E, and Ishii M. Effects of insufficient sleep on blood pressure monitored by a new multibiomedical recorder. Hypertension 27: 1318-1324, 1996.

52. Tofler GH, Stone PH, Maclure M, Edelman E, Davis VG, Robertson T, Antman EM, and Muller JE. Analysis of possible triggers of acute myocardial infarction (The MILIS study). Am J Cardiol 66: 22-27, 1990.

53. Van Dongen HP, Maislin G, Mullington JM, and Dinges DF. The cumulative cost of additional wakefulness: dose response effects on neurobehavioral functions and sleep physiology from chronic sleep restriction and total sleep deprivation. Sleep 26: 117-126, 2003.

54. West R. The transient nature of executive control processes in younger and older adults. Eur J Cogn Psychol 13: 91-105, 2001.

55. Zeger SL, Liang KY. Longitudinal data analysis for discrete and continuous outcomes. Biometrics 42: 121-30, 1986.

56. Zollei E, Paprika D, and Rudas L. Measures of cardiovascular autonomic regulation derived from spontaneous methods and the Valsalva maneuver. Auton Neurosci 103: 100-105, 2003. 